\title{
The prevalence of lacunar infarct decreases with aging in the elderly: a case-controlled analysis
}

\author{
This article was published in the following Dove Press journal: \\ Clinical Interventions in Aging \\ 26 May 2016 \\ Number of times this article has been viewed
}

\author{
Zhiyou Cai ${ }^{\prime}$ \\ Wenbo $\mathrm{He}^{\prime}$ \\ Chuan-yong Peng ${ }^{2}$ \\ Jin Zhou ${ }^{2}$ \\ Qi-lan $\mathrm{Xu}^{2}$ \\ Zong-shan $\mathrm{Wu}^{2}$ \\ 'Department of Neurology, Renmin \\ Hospital, Hubei University of \\ Medicine, Shiyan Renmin Hospital, \\ Shiyan, Hubei Province, ${ }^{2}$ The \\ Examination Center of Magnetic \\ Resonance Imaging, the Lu'an \\ Affiliated Hospital of Anhui Medical \\ University, Lu'an People's Hospital, \\ Lu'an, Anhui Province, People's \\ Republic of China
}

\begin{abstract}
Background and purpose: Lacunar infarct (LI) is well known as a heterogeneous primary disorder of cerebral small vessel. Compelling results have demonstrated that age is a risk factor to the prevalence of LI. However, the relationship between age and the prevalence of LI remains obscure. It is essential to note the relationship between age and the prevalence of LI through more clinical data.
\end{abstract}

Methods: A total of 3,500 patients were included in the case-controlled study. All data were collected from the Examination Center of Magnetic Resonance Imaging, Lu'an People's Hospital from January 2014 to December 2015. A primary discharge diagnosis of LI was done, and all subjects were evaluated as retrospective data. The relationship between the risk factors and the prevalence of diabetes and the relationship between age and the prevalence of diabetes was analyzed. A chi-square test was used to analyze the associations between different variables. A one-way analysis of variance was used to test the equality of three or more means at one time by using variances. Statistical significance was defined as a $P$-value of $<0.05$.

Results: The one-way analysis of variance demonstrated that the prevalence of LI increased with age before 60 years and decreased with age after 69 years. The same results were found in both the male and the female subjects. These results showed that the age-related risk factors (hypertension, diabetes, cerebral infarct, cardiovascular diseases, smoking, and drinking) have no relationship with the prevalence of LI on the basis of age. There is a significant difference among the different age ranges $(P=0.0006)$. Two-tailed $P$-value (unpaired $t$-test) showed the mean significant difference between 30-39 years and 40-49 years $(P=0.009)$ and between $70-79$ years and $80-100$ years $(P=0.0196) . F$-test (to compare variances) demonstrated that the variances of the different age ranges are significantly different between 30-39 years and 40-49 years $(P=0.0002)$, between $40-49$ years and 50-59 years $(P=0.0424)$, and between $70-79$ years and $80-100$ years $(P=0.0003)$.

Conclusion: The age-related risk factors (hypertension, diabetes, cerebral infarct, cardiovascular diseases, smoking, and drinking) have no relationship with the prevalence of LI on the basis of age. A decreasing prevalence of LI with aging occurs in the elderly, while the prevalence of LI increases with aging in the young and in adults. This investigation implicates that age is not a risk factor for LI in the elderly.

Keywords: lacunar infarct, prevalence, age, risk factor

\section{Introduction}

Lacunar infarct (LI), also known as lacunar stroke, is a small stroke that results from damage to, or a blockage of, small size penetrating brain arteries and arterioles that provide blood to the brain's deep structures within the internal capsule, basal ganglia, thalamus, pons, and cerebral white matter. ${ }^{1}$ LI may be asymptomatic, showing up only on brain imaging, or may have depression, pure motor, pure sensory, ataxic, or 
mixed motor and sensory symptoms. ${ }^{2}$ A large number of results have shown that the prevalence of LI increases with age worldwide. ${ }^{3-5}$ With the rapid progress of aging, LI will become an important impact on family and is harmful to the society. Therefore, the prevention and treatment of LI are important.

It is well accepted that LI is closely associated with the following risk factors: hypertension, diabetes, cardiovascular diseases, the history of cerebral infarct, smoking, and drinking. ${ }^{6-8}$ However, the relationship between age and the prevalence of LI remains obscure. It is essential to clarify the relationship between age and the prevalence of LI with more clinical data. We sought to investigate the clinical data of LI from January 2014 to December 2015 at our hospital in Central China and to further clarify the relationship between the prevalence of LI and age. The relationship between the prevalence of LI and the risk factors was also analyzed based on the age. The present clinical investigation has demonstrated that the trend of the prevalence of LI decreases with aging in the elderly after 69 years and increases with aging before 60 years.

\section{Methods}

\section{Study design}

This case-controlled study was a retrospective cohort analysis implemented in the Examination Center of Magnetic Resonance Imaging, Lu'an People's Hospital in Lu'an, Anhui Province, People's Republic of China, which cares for $\sim 70,000$ inpatients and 800,000 outpatients per year. Cases of LI were identified by magnetic resonance imaging (MRI) examination, and control were those who did not. The review of patient's data before its commencement was approved by the institutional medical ethics committee of Renmin Hospital, Hubei University of Medicine. This analysis was executed in accordance with the approved guidelines. The requirement for informed consent was waived due to the retrospective nature of this analysis.

\section{Data collection}

The MRI records of adult ( $\geq 16$ years) patients with LI obtained from the Examination Center of Magnetic Resonance Imaging of our hospital between January 2014 and December 2015 were reviewed. A total of 3,500 patients, which contain all MRI data, were selected from inpatients and outpatients. All selected cases underwent examinations with conventional MRI sequences (including gradient echo sequence T1 and T2, T2 fluid attenuation inversion recovery, or diffusion-weighted imaging). Lacunes were defined by MRI as focal, discrete areas of apparent ischemic infarction measuring $>5 \mathrm{~mm}$ and $<15 \mathrm{~mm}$ at diameter. There were no uncertain cases for discussion. The clinical and demographic characteristics of all patients, including their age, sex, risk factors, initial vital signs, laboratory findings, and clinical outcomes, were obtained from the MRI Examination Center.

\section{Statistical analysis}

All statistical analyses were performed using SPSS for Windows Version 18.0 (SPSS Inc., Chicago, IL, USA). A chi-square test was introduced to analyze the associations between two different variables. A one-way analysis of variance was used to test the equality of three or more means at one time by using variances. A $P$-value of $<0.005$ was taken to indicate statistical significance.

\section{Results}

\section{The analysis of age distribution for $\mathrm{LI}$}

The total cases were 3,500, including 1,032 LI patients and 2,468 non-LI ones. There are seven age ranges (10-29 years, 30-39 years, 40-49 years, 50-59 years, 60-69 years, 70-79 years, and 80-100 years), which each age range has 500 cases. In all, 1,032 LI cases included 544 males and 488 females.

The data showed that the prevalence of LI increased with age before 60 years and decreased with age after 69 years. The same results were found in both the male and the female subjects (Figure 1 and Table 1). The one-way analysis of variance demonstrated that the prevalence of LI is associated with age, indicating that the prevalence of LI increased with age before 60 years and decreased with age in the elderly after 69 years.

\section{The relationship between risk factors and the prevalence of $\mathrm{LI}$}

The association between the clinical risk factors and the prevalence of LI on the basis of age had been demonstrated in Table 2. These results showed that the age-related risk factors (hypertension, diabetes, cerebral infarct, cardiovascular diseases, smoking, and drinking) have no relationship with the prevalence of LI on the basis of age. There is a significant difference among the different age ranges in Table 3 ( $P=0.0006)$. Two-tailed $P$-value (unpaired $t$-test) showed the mean significant difference between 30-39 years and $40-49$ years $(P=0.009)$ and between $70-79$ years and $80-100$ years $(P=0.0196) . F$-test (to compare variances) demonstrated that the variances of the different age ranges are significantly different between 30-39 years 

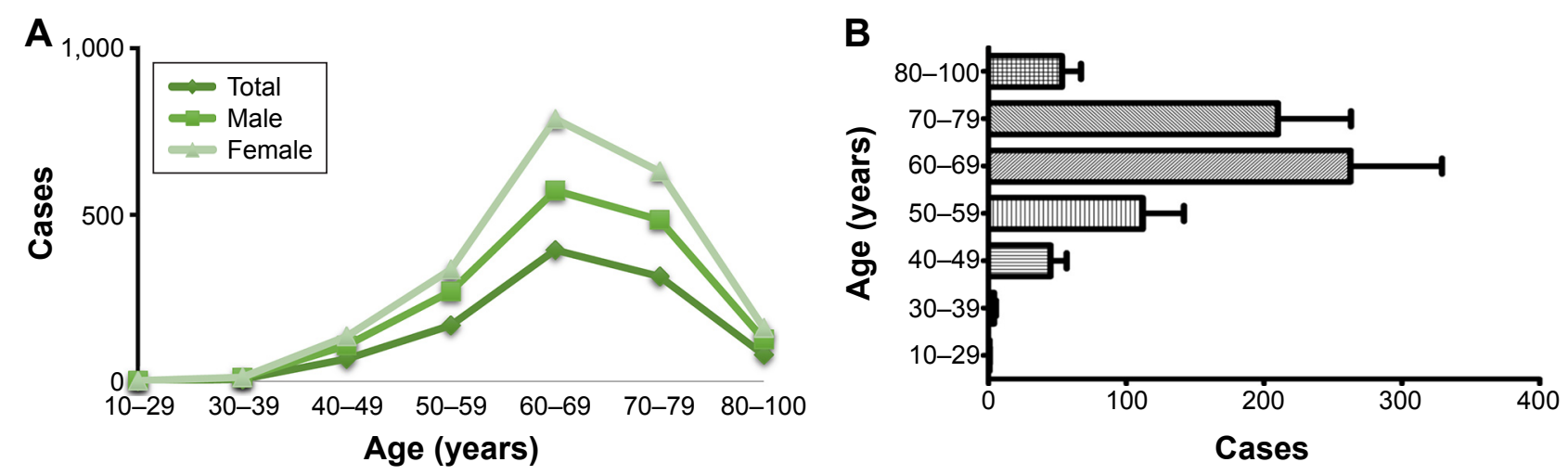

Figure I Age distribution of $\mathrm{LI}$ patients.

Notes: The prevalence of $\mathrm{LI}$ varies by age group, with the highest prevalence of collected cases occurring in age between 60 years and 69 years. (A) Trend of age distribution. (B) Distribution of LI by different age.

Abbreviation: LI, lacunar infarct.

and 40-49 years $(P=0.0002)$, between $40-49$ years and 50-59 years $(P=0.0424)$, and between $70-79$ years and $80-100$ years $(P=0.0003)$. These results indicate that a decreasing prevalence of LI with aging occurs in the elderly, especially after 70 years, while the prevalence of LI increases with aging in the young and adults before 59 years.

\section{Discussion}

LI is a small cavitated lesion no larger than $20 \mathrm{~mm}$ in diameter in the distal distribution of deep penetrating vessels, including lenticulostriate, thalamoperforating, and pontine perforating arteries. ${ }^{1,9} \mathrm{LI}$ is a common pathological entity that can result in various clinical manifestations in the adult and elderly population. In this study, the one-hospital clinical data were, retrospectively, assayed, and the patients with a diagnosis of LI by MRI were selected from an examination center of MRI. This clinical investigation identified that there was no relationship between the prevalence of LI and the agerelated risk factors (hypertension, diabetes, cerebral infarct, cardiovascular diseases, smoking, and drinking) according to the age range. This study has found that the prevalence of LI increases with age before 60 years and decreases with age after 69 years in the elderly. However, this result is different from the previous reports that the prevalence of LI increases with aging. Therefore, this analysis indicates that aging is not a contributor to the prevalence of LI in the elderly, in spite of the contrary to the precious evidence data that the prevalence of LI is proportional to the progress of age.

Increasing imaging and clinical research has demonstrated that LI is an age-related silent lacunar stroke and a common occurrence in the elderly. ${ }^{10} \mathrm{LI}$ is the most common type of stroke in the Japanese population, ${ }^{11,12}$ the Caucasian, ${ }^{13}$ the African American, ${ }^{14}$ the Caribbean blacks, ${ }^{13,15}$ the Chinese population, ${ }^{16,17}$ and worldwide. It was demonstrated that age-specific incidence rates for lacunar stroke in south Alabama were higher in blacks than whites, and highest for black females when the age-adjusted rates for initial stroke were 109 per 100,000 for whites and 208 per 100,000 for blacks, ${ }^{18}$ indicating the black/white differences in stroke rate. ${ }^{19}$ It was also found that African Americans have more lacunar stroke and more severe prestroke disability than Caucasians. $^{20,21}$ Increasing studies pointed to the racial differences in ischemic cerebrovascular disease, including lacunar stroke. ${ }^{15,20,22,23}$ Clinical data evidenced that the racial

Table I The distribution of LI by different age range and sex

\begin{tabular}{|c|c|c|c|c|c|c|c|c|c|c|c|}
\hline \multirow[t]{2}{*}{ Sex } & \multicolumn{7}{|c|}{ Age distribution (years) } & \multirow[t]{2}{*}{$\mathbf{N}$} & \multirow[t]{2}{*}{$P$-value } & \multirow[t]{2}{*}{$\boldsymbol{F}$} & \multirow[t]{2}{*}{$R^{2}$} \\
\hline & $10-29$ & $30-39$ & 40-49 & 50-59 & 60-69 & 70-79 & $80-100$ & & & & \\
\hline Total & 500 & 500 & 500 & 500 & 500 & 500 & 500 & 3,500 & & & \\
\hline \multirow[t]{2}{*}{$\mathrm{LI}(\mathrm{M}+\mathrm{F})$} & I & 6 & 67 & 168 & 394 & 315 & 80 & 1,032 & 0.0269 & 8.473 & 0.1745 \\
\hline & $0.2 \%$ & $1.2 \%$ & $13.4 \%$ & $33.6 \%$ & $78.8 \%$ & $63 \%$ & $16 \%$ & & & & \\
\hline \multirow[t]{2}{*}{ Male (LI) } & I & 5 & 41 & 102 & 179 & 170 & 46 & 544 & 0.0295 & 8.077 & 0.2891 \\
\hline & $0.2 \%$ & $1 \%$ & $8.2 \%$ & $20.4 \%$ & $35.8 \%$ & $34 \%$ & $2.3 \%$ & & & & \\
\hline \multirow[t]{2}{*}{ Female (LI) } & 0 & I & 27 & 66 & 215 & 145 & 34 & 488 & 0.0485 & 6.739 & 0.2825 \\
\hline & $0.0 \%$ & $0.2 \%$ & $1.35 \%$ & $3.3 \%$ & $43 \%$ & $29 \%$ & $1.7 \%$ & & & & \\
\hline
\end{tabular}

Abbreviations: $F$, female; LI, lacunar infarct; $M$, male. 

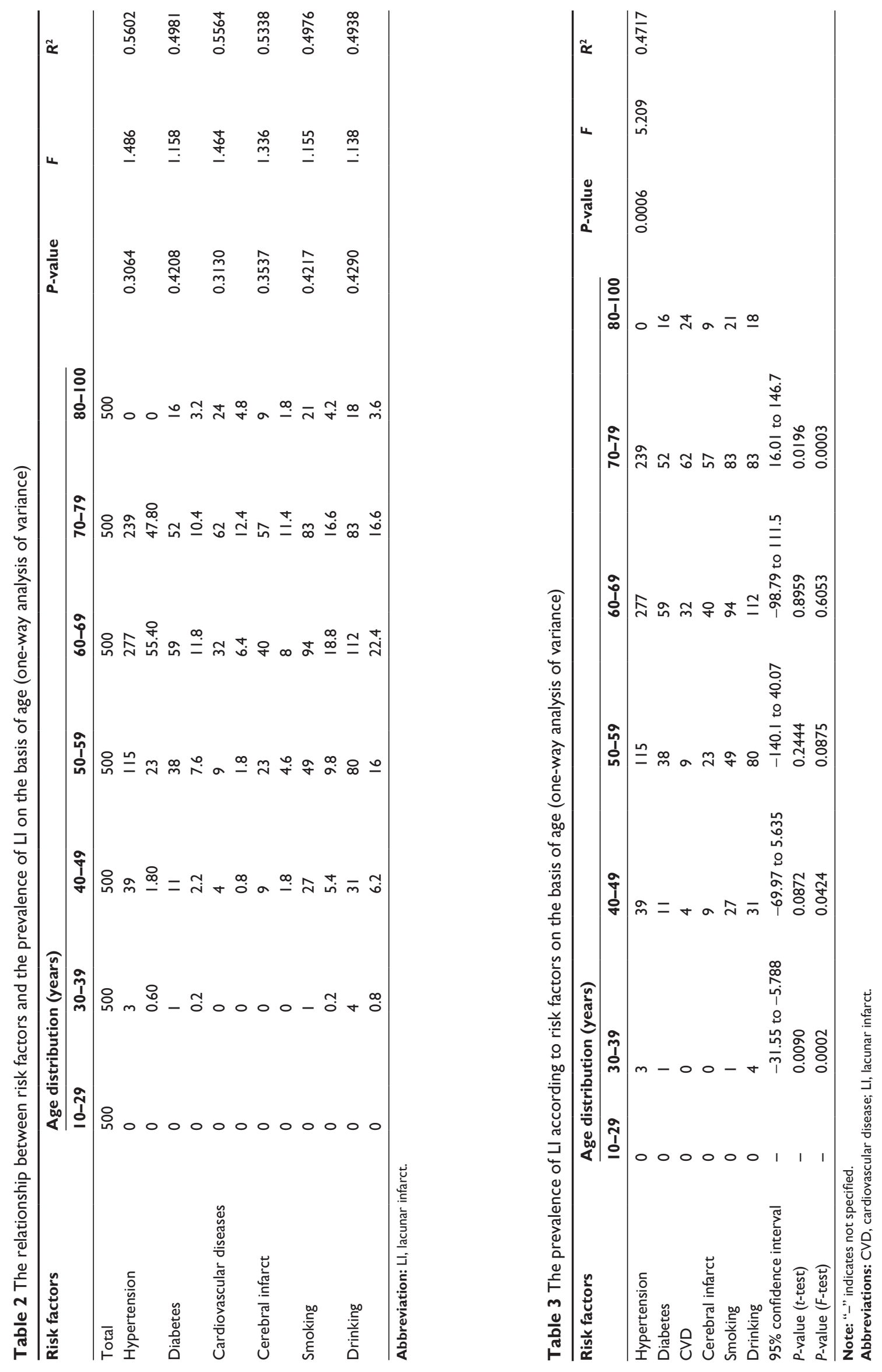
differences in lacunar stroke are associated with the different diet, lifestyle, habits, air pollution, and so on, interfering with the age-related involvement. ${ }^{15,21,23}$ Compelling clinical studies evidenced that LI has an age-adjusted incidence comparable with the incidence of large vessel atherosclerotic stroke. ${ }^{24-26}$ The trend of LI prevalence is increasing with age. ${ }^{25,27}$ Different from these previous research results, this investigation found that the prevalence of LI increases with age before 60 years and decreases with age after 69 years in the elderly, suggesting that aging is not a contributor to the prevalence of LI in the elderly after 69 years. The implications of these findings may require different interventions in the elderly.

It is well known that LI is the most important small vessel cerebrovascular disease, accounting for $20 \%-25 \%$ of all ischemic strokes. ${ }^{6,28} \mathrm{LI}$ has been involved in the two major vascular pathologies with small size penetrating brain arteries and arterioles: thickening of the arterial media and obstruction of penetrating arteries. ${ }^{1,29}$ Considering that the prevalence of LI increases with age before 60 years and decreases with age after 69 years in the elderly, we inferred the pathogenesis of LI that age around 60 years is a fragile and vulnerable period to be easy to induce the small vascular pathologies and the occurrence of LI. It is possible that "lacune" ever cavitated from LI will be gradually absorbed and disappeared with the progress of aging. Therefore, it may be important to have a comprehensive prevention for LI before and during the fragile and vulnerable period. This study is not a randomized and controlled investigation; therefore, further studies have to be performed to determine these conclusions.

\section{Acknowledgments}

This work was supported by grants from the Natural Science Foundation of Hubei Province (2015CFB260), and the Hubei Province Health and Family Planning Scientific Research Project (WJ2015MB219) and the Shiyan Natural Science of Renmin Hospital, Hubei University of Medicine to Dr Zhiyou Cai.

\section{Disclosure}

The authors report no conflicts of interest in this work.

\section{References}

1. Caplan LR. Lacunar infarction and small vessel disease: pathology and pathophysiology. J Stroke. 2015;17(1):2-6.

2. Wu RH, Li Q, Tan Y, Liu XY, Huang J. Depression in silent lacunar infarction: a cross-sectional study of its association with location of silent lacunar infarction and vascular risk factors. Neurol Sci. 2014;35(10): $1553-1559$.

3. Sun XG, Wang T, Zhang N, Yang QD, Liu YH. Incidence and survival of lacunar infarction in a southern Chinese population: a 7-year prospective study. Brain Inj. 2015;29(6):739-744.
4. Koppelmans V, Vernooij MW, Boogerd W, et al. Prevalence of cerebral small-vessel disease in long-term breast cancer survivors exposed to both adjuvant radiotherapy and chemotherapy. J Clin Oncol. 2015;33(6): 588-593.

5. Basile AM, Pantoni L, Pracucci G, et al; LADIS Study Group. Age, hypertension, and lacunar stroke are the major determinants of the severity of age-related white matter changes. The LADIS (leukoaraiosis and disability in the elderly) study. Cerebrovasc Dis. 2006;21(5-6): 315-322.

6. Li Y, Liu N, Huang Y, Wei W, Chen F, Zhang W. Risk factors for silent lacunar infarction in patients with transient ischemic attack. Med Sci Monit. 2016;22:447-453.

7. Yan B, Peng L, Dong Q, et al. Reverse-dipper pattern of blood pressure may predict lacunar infarction in patients with essential hypertension. Eur J Neurol. 2015;22(6):1022-1025.

8. Shin DW, Lee KB, Seo JY, et al. Association between hypertriglyceridemia and lacunar infarction in type 2 diabetes mellitus. $J$ Stroke Cerebrovasc Dis. 2015;24(8):1873-1878.

9. $\mathrm{Ng} \mathrm{M}$, Singh P. Use of lacunar infarction as a marker of small vessel disease. Eur J Neurol. 2015;22(3):e39.

10. Palacio S, McClure LA, Benavente OR, Bazan C 3rd, Pergola P, Hart RG. Lacunar strokes in patients with diabetes mellitus: risk factors, infarct location, and prognosis: the secondary prevention of small subcortical strokes study. Stroke. 2014;45(9):2689-2694.

11. Hirose $T$, Hashimoto M, Totsune $K$, et al. Association of (pro)renin receptor gene polymorphisms with lacunar infarction and left ventricular hypertrophy in Japanese women: the Ohasama study. Hypertens Res. 2011; 34(4):530-535.

12. Taguchi A, Miki M, Muto A, et al. Association between oral health and the risk of lacunar infarction in Japanese adults. Gerontology. 2013; 59(6):499-506.

13. Corbin DO, Poddar V, Hennis A, et al. Incidence and case fatality rates of first-ever stroke in a black Caribbean population: the Barbados register of strokes. Stroke. 2004;35(6):1254-1258.

14. Nyquist PA, Bilgel MS, Gottesman R, et al. Extreme deep white matter hyperintensity volumes are associated with African American race. Cerebrovasc Dis. 2014;37(4):244-250.

15. Koch S, Gupta R, McClendon MS, Romano JG. Racial-ethnic differences in lacunar infarction in a multiethnic stroke population. J Stroke Cerebrovasc Dis. 2013;22(2):107-112.

16. Tsai CF, Anderson N, Thomas B, Sudlow CL. Risk factors for ischemic stroke and its subtypes in Chinese vs Caucasians: systematic review and meta-analysis. Int J Stroke. 2015;10(4):485-493.

17. Tsai CF, Thomas B, Sudlow CL. Epidemiology of stroke and its subtypes in Chinese vs white populations: a systematic review. Neurology. 2013; 81(3):264-272.

18. Gross CR, Kase CS, Mohr JP, Cunningham SC, Baker WE. Stroke in south Alabama: incidence and diagnostic features - a population based study. Stroke. 1984;15(2):249-255.

19. Friday G, Lai SM, Alter M, et al. Stroke in the Lehigh Valley: racial/ ethnic differences. Neurology. 1989;39(9):1165-1168.

20. Singh R, Cohen SN, Krupp R, Abedi AG. Racial differences in ischemic cerebrovascular disease. J Stroke Cerebrovasc Dis. 1998;7(5):352-357.

21. Hassaballa H, Gorelick PB, West CP, Hansen MD, Adams HP Jr. Ischemic stroke outcome: racial differences in the trial of danaparoid in acute stroke (TOAST). Neurology. 2001;57(4):691-697.

22. Hajat C, Dundas R, Stewart JA, et al. Cerebrovascular risk factors and stroke subtypes: differences between ethnic groups. Stroke. 2001;32(1):37-42.

23. Wolma J, Nederkoorn PJ, Goossens A, Vergouwen MD, van Schaik IN, Vermeulen M. Ethnicity a risk factor? The relation between ethnicity and large- and small-vessel disease in White people, Black people, and Asians within a hospital-based population. Eur J Neurol. 2009; 16(4):522-527.

24. Zhang C, Wang Y, Zhao X, et al; Chinese IntraCranial AtheroSclerosis Study Group. Factors associated with severity of leukoaraiosis in firstever lacunar stroke and atherosclerotic ischemic stroke patients. J Stroke Cerebrovasc Dis. 2014;23(10):2862-2868. 
25. Lawrence ES, Coshall C, Dundas R, et al. Estimates of the prevalence of acute stroke impairments and disability in a multiethnic population. Stroke. 2001;32(6):1279-1284.

26. Le Pira F, Giuffrida S, Giammona G, Saponara R, Lanza S, La Spina V. Leukoaraiosis and lacunar infarcts in ischemic stroke: role of age and vascular risk factors. Ann Ital Med Int. 1997;12(2):72-75.

27. Kitagawa K, Miwa K, Yagita Y, Okazaki S, Sakaguchi M, Mochizuki H. Association between carotid stenosis or lacunar infarction and incident dementia in patients with vascular risk factors. Eur J Neurol. 2015; 22(1):187-192.
28. Forster A, Murle B, Bohme J, et al. Perfusion-weighted imaging and dynamic 4D angiograms for the estimation of collateral blood flow in lacunar infarction. J Cereb Blood Flow Metab. Epub 2015 Oct 14.

29. Araki Y, Kumakura H, Kanai H, et al. Prevalence and risk factors for cerebral infarction and carotid artery stenosis in peripheral arterial disease. Atherosclerosis. 2012;223(2):473-477.

\section{Publish your work in this journal}

Clinical Interventions in Aging is an international, peer-reviewed journal focusing on evidence-based reports on the value or lack thereof of treatments intended to prevent or delay the onset of maladaptive correlates of aging in human beings. This journal is indexed on PubMed Central, MedLine,
CAS, Scopus and the Elsevier Bibliographic databases. The manuscript management system is completely online and includes a very quick and fair peer-review system, which is all easy to use. Visit http://www.dovepress. com/testimonials.php to read real quotes from published authors. 